\title{
Silencing Deafness: Displacing Disability in the Nineteenth Century
}

\author{
Esme Cleall, University of Sheffield
}

\begin{abstract}
'We should try ourselves to forget that they are deaf. We should try to teach them to forget that they are deaf.'
\end{abstract}

So spoke Alexander Graham Bell, the British inventor of the telephone and deaf educationalist, in a controversial speech of 1884 (cited in Ladd 2003: 129). The speech, reproduced as a pamphlet, Memoir Upon the Formation of a Deaf Variety of the Human Race (1883), was contentious at the time and has since been widely criticised by disability activists as eugenic. In it Bell advocated the intermarriage of deaf and hearing in order to breed-out deafness, to eradicate what he labelled a 'variety' of humanity that he saw as defective. Before that goal could be achieved, Bell hoped that deaf people could be taught to articulate spoken language to the extent that their deafness could be forgotten (Bell 1883). Bell was not arguing for an end to the discrimination that surrounded deafness, as may be implied through an 'equal opportunities' reading of his words. Rather, he actively sought the forgetting of deafness in the deaf and the ultimate rendering of disability itself a thing of the forgotten past. This desire, common in a latenineteenth century British culture of fostering 'normalcy,' identified difference (be it the difference of ethnicity, sexuality, or disability) as something undesirable, and the forgetting of that difference an aspiration.

In his 2010 memoir, Deafness of the Mind, the deaf author Kevin Fitzgerald also used the idea of 'forgetting' to evoke deaf education. His memoir's subtitle, The Forgotten 
Children of Boston Spa, points to the deaf 'inmates' of the St John's Institution for the Deaf and Dumb, in Yorkshire England, where Fitzgerald was himself a pupil in the 1950s. This is an account of his 'incarceration' at the hands of the Catholic Church and of how 'generations of deaf children were treated as second class citizens' (Fitzgerald 2010). Fitzgerald's understanding of forgetting is linked to the discrimination deaf people have long faced and the way in which they have been marginalised from society and from history. Here, Fitzgerald evokes two issues typical of many examples of the 'history of forgetting': the repression of painful memories of abuse and the marginalisation of minority histories. The very different meanings Bell and Fitzgerald intend by 'forgetting' point to the contours of a complicated process: the relationship between 'forgotten' histories and the active process of 'forgetting.'

There is no doubt that experiences of disability, including deafness, have been historiographically marginal, even within social and cultural history. ${ }^{1}$ The excellent work of many historians of disability, including that produced by community activists, has, for the most part, been self-contained, and is often treated as a different kind of history from that of other social groups and processes. Whilst some historians of disability have drawn attention to the potential utility of examining disability alongside other socially constructed categories of difference, such as ethnicity, for the most part disability has been forgotten as a way of being, a source of identity, and a target of prejudice and discrimination (Ladd 2003: 1-26). Historians of memory have even used ideas of disability as metaphors for forgetting-stories and experiences which have fallen on 'deaf ears.' Ann Laura Stoler, to take just one example, has recently discussed the 'aphasia' surrounding issues of colonialism and immigration in French history, a cognitive disability she explains psychologists see as a 'comprehension deficit,' a partial 'knowledge loss' or a 'difficulty comprehending “structural relationships”' (Stoler 2001: 145). The metaphor is perhaps useful in capturing the fragmented representation of colonialism with which Stoler is concerned, but it is interesting to reflect on her use of the phrase 'disabled histories' to encapsulate the process of forgetting itself. One also wonders about the effect of the metaphors so often used by social historians about

\footnotetext{
${ }^{1}$ The relationship between 'disability’ and 'deafness' is a complicated one. Many politically Deaf groups in the late-twentieth and early twentieth-first centuries have powerfully argued that deafness is not a disability but a 'way of being' and a suppressed cultural group. In this article, however, I am discussing deafness and disability together because this is how it was understood by those writing about deafness in the work I'm reviewing here, and the labelling of deafness as disability (or rather 'infirmity') was, I argue an important element of its historically 'forgetting.'
} 
giving 'voice to the voiceless,' and listening to 'the silences' in the archives (and the common, if inaccurate, perception that deaf people are voiceless and silent) on conceiving deaf experience, in particular, as an area for historical research.

But does the academically and culturally marginal place occupied by Deaf history mean that the experience of deafness has been forgotten? And what indeed constitutes a 'history of forgetting'? How does it differ from the 'hidden histories' (Morgan 1999) of marginalised groups (including sign-language users) and the problems of scant sources and incompatible language fluencies in accessing them? As many commentators from Freud on have demonstrated, forgetting is not simply experience overlooked or misplaced, but is an active process through which certain feelings and memories are excluded, repressed or silenced from an individual or collective consciousness (Radstone \& Schwarz 2010). Much of the existing work on historical memory and forgetting concentrates on the repression of violence, such as the forgetting and remembering of conflict and conquest; the refusal of guilt, as in the forgetting of colonialism and collaboration; or the wary treatment of histories of sectarianism and suppression, wrought with contemporary resonances. Although less notorious, many Deaf activists have constructed the treatment of the deaf as just such an issue, a process of medical and epistemological violence, cultural colonialism and linguistic suppression. Haran Lane (1992), for example, has described members of Deaf communities as linguistic minorities, with distinct cultures, who have suffered and continue to suffer the 'physical subjugation of a disempowered people, the imposition of alien language and mores, and the regulation of education on behalf of the [hearing] colonizer's goals.' Some of these processes, particularly those of cruelty and maltreatment, lie behind Fitzgerald's implication that the abuse suffered by the children of Boston Spa has been forgotten. But it is not these elements upon which I focus here. Instead I examine how the very discussion of the deaf, particularly in the nineteenth century, was haunted by evocations and conceptions of 'silence' and 'forgetting.' This brings me back to Bell's construction of the deaf.

When Bell, a hearing man concerned with educating the deaf into 'normality,' implied that deafness, and ultimately the deaf, were best erased, he was speaking as one of many in the late nineteenth-century Anglophone world who actively sought to forget deafness. It is striking how common this metaphor was. The word 'forgetting' creeps into 
numerous discussions of deafness in the writing of Bell's contemporaries, both deaf and hearing. Some, including Bell, were overt in their desire to forget deafness. Others used the term ambivalently and sometimes metaphorically. Some even pleaded that people who were deaf were not forgotten. But, though varied, the use of the imagery of forgetting and silence to evoke deafness is recurrent, and may, therefore, be seen to reveal something about how deaf experience can be approached as a 'history of forgetting.' It is particularly suggestive given that the use of such language occurred at the same time as deafness began to be popularly acknowledged as a social category in Europe and North America.

\section{Locating deafness and finding 'the deaf'}

Like race, gender and other categories of difference, disability is a relational discourse. Whilst what it means to be disabled is read off a variety of visible and medical markers, 'disability' has no inherent meaning, simply being the way in which those with a perceived impairment come to be socially disadvantaged. Yet, although a social process, disability is often naturalised as a state of being that is different from and inferior to an imagined 'norm.' Deafness too is subject to social definition (in contemporary British society being profoundly deaf is considered disabling, being tone deaf is not). Deaf activists have used 'Deaf' to indicate a deaf identity and 'deaf' as an adjective, a distinction which illuminates the fluid meanings of what it means to be deaf. ${ }^{2}$ Becoming hard-of-hearing in older age, being pre-lingually deaf, being profoundly deaf, and being 'mute,' are significantly different ways of being (though in nineteenth-century discussions of 'the deaf and dumb' many of these distinctions are conflated). Because disability is socially constructed, what it means to be deaf depends enormously on the attitudes of a given society to impairment as well as the resources and education available to deaf people. Deafness constitutes different things at different moments in the past as it has in different places and societies.

Deafness has very long associations and symbolic investments in western culture. From Leviticus and its prohibitive stance towards disability and impairment in the Hebrew Bible, to Jesus' miraculous opening of deaf ears in the New Testament, biblical teachings have ensured that deafness has been be highly, if contradictorily, symbolically

\footnotetext{
2 This is a distinction I generally find very useful, but one that I have not used in this article as the difference between the terms did not exist in the nineteenth century and applying them retrospectively requires a problematic assumption of identity.
} 
invested (Cleall 2013). But, despite this, deaf people in British society were not identified as a social category 'The Deaf' or 'The Deaf and Dumb' until the late eighteenth century. During the nineteenth century, this category consolidated and there was a considerable change and reconceptualisation of what it meant to be deaf in the European and Anglophone world, as it was a time when other categories of difference were also being demarcated and codified. Throughout the century, a coincidence of factors and developments subjected people who were deaf to an unprecedented degree of scrutiny.

Nineteenth-century medical advancements gave doctors increased confidence in their ability to identify and cure various disabilities and diseases. The fact that little could be done by way of medical intervention in the vast majority of cases of profound deafness did little to hinder the enthusiasm for trying: holes were drilled through deaf children's jaws, caustic substances were poured into their ears, ear-drums were pierced, white-hot metal was applied, and in some cases their skulls were fractured behind the ear. Numerous surgical attempts at 'cure' resulted in failure (and were sometimes fatal) (Carpenter 2009: 115).

At the same time, a rapidly growing group of teachers of the deaf declared they could 'help’ deaf people and advocated new techniques and instruments which they claimed could enable deaf-mute people to acquire speech. Others were intent, not on forcing deaf-mute people to articulate spoken language, but on teaching them to read and write it as a replacement for oral communication. Such measures were seized upon by philanthropists and missionaries, who argued that the deaf were literally prevented from hearing the Word of God and claimed the 'Deaf, Who on That Account Do Not Attend Church' as a problematic social group, and set up deaf churches and prayer groups (Society for the Propagation of Christian Knowledge 1864). Within the newly founded schools, churches, and institutions for the deaf that emerged from these activities, deaf people, able to come together within organised structures, developed distinctive social identities themselves. The use of manual sign-languages spread rapidly.

All these developments served to make the deaf an identifiable community subject to an unprecedented amount of attention from both educational and medical 'experts' and from the lay public. The 1861 Census (1863, vol. III: 55-166), for example, went into considerable depth about deafness, including sections on 'Distribution of the Deaf-and- 
Dumb in England,' the 'Causes of Congenital Deafness, 'Causes of Acquired Mutism,' 'Ages of Male and Female Mutes’ and the 'Necessity of Special Instruction.' Societies were established to 'educate,' 'rescue,' 'civilise' and Christianise deaf children, particularly those from the working classes. The discourses on deafness produced by these varied groups and by deaf people themselves were extremely diverse, characterised by discussion, debate and disagreement about the intentions and execution of their interventions.

Nevertheless, several tropes carried across these divergences. One was that this was a moment that many contemporaries often framed in terms of a sudden finding or remembering of the deaf. Philanthropists and educationalists spoke as though they were discovering deaf children who they constructed as 'forgotten' by society and even by their own families. Evangelical philanthropists urged the hearing not to forget the 'class of your fellow-creatures' who 'because one gift was wanting' were 'excluded from their natural share in human rights, and degraded ... from their rank as human beings.' They begged the hearing to 'rescue' the deaf from this 'forlorn condition' and introduce them to 'unfolding the truths and the hopes of Religion' (Account of the General Institution ... 1814: 3). Spurred on by accounts of deaf schools in London and Edinburgh, enthusiasts for deaf education in the provinces began a search for the deaf in their own localities. Mr Gordon (1831: 22), an advocate of deaf education, wrote 'Liverpool is known to contain 100 deaf mutes, but judging from its great population, and the difficulty which is experienced in discovering those objects, it is to be feared, that not more than one half of their number has yet been discovered in that town.' Discovering the unseen, unheard places of the deaf, is reminiscent of other 'discoveries' of the nineteenth century, from 'Darkest Africa' to 'Outcast London,' as is the passive construction of the deaf as 'objects.' The predominant strain of language here is 'remembering' rather than 'forgetting,' but this is grounded in the assumption that, ordinarily, deaf people were easy to forget.

A second trope common across these divergent discourses was that the deaf could be defined through their otherness, and could be categorised and codified as a distinct social group. This too could motivate and facilitate their forgetting. As Henri-Jacques Striker (1999) has demonstrated, fear of disability has recurred in many guises in different ages, and is in part about the fear of the 'unlike.' From this perspective, Bell's 
work can be read as an assimilationist desire to forget difference, as can other projects of deaf education that had at their heart the desire to create 'normality.'

It is not surprising that the very moment that deafness became solidified as a marked category, a social group, and a subject of pedagogical and medical 'expertise,' it was accompanied by a discourse of forgetting, removal and displacement. This is a pattern that can, I believe, be identified far wider than in writings about disability, still less deafness. Rather, it reflects the discomfort in nineteenth-century society with facing difference, the desire to construct normality, the tendency to exclude those who are different from the imagined nation, and the desire that difference be forgotten, that the deaf, as Bell put it, 'try and forget that they are deaf.' The desire to forget this newly identified form of 'deviance' was sometimes expressed overtly (as in the case of Bell). However, it was also expressed through the frequency with which tropes of forgetting and remembering appear in writings about deafness, where the values invested in 'forgetting' (and also 'remembering') are more ambiguous. It is these tendencies that the remainder of the article seeks to explore.

\section{Out of sight out of mind: the deaf institution as a space of forgetting}

The nineteenth century saw the increased institutionalisation of people with disabilities, including deaf people, within asylums and residential schools. In a move not dissimilar to what Foucault named the 'Great Confinement' of the 'insane,' the deaf were increasingly segregated from 'normal' society (Striker 1999: 66). Under the Enlightenment drive towards 'civilisation,' the education of the deaf became a subject of increased medical and pedagogic expertise and a matter of public concern. In Britain, the first school for deaf children, the Braidwood institution, opened in Edinburgh in 1760. In 1792 the first public institution opened in London. Similar institutions soon sprang up all over the country. By the time of the 1881 census there were currently 317 pupils at the London Asylum (and at its branch in Margate), 138 pupils in the Manchester Institution for the deaf-and-dumb, 109 pupils at the Edgbaston school, 100 at the Liverpool school, and 65 pupils at the institution in Exeter, 105 at the school in Brighton, 77 in Newcastle-upon-Tyne and 97 at the Brighton Institution (Census 1871). These schools signified various kinds of segregation. Boarding schools offered families of deaf children the opportunity to send away, and possibly forget, the 'problem' of 
disability, at least on an everyday basis. Day schools for deaf children ensured that the deaf were educated separately and differently from hearing children.

Part of the methodology of these asylums was based on the pedagogy of forgetting. In the early and mid-nineteenth century, the methods used to instruct deaf children varied and some teachers of the deaf used manual sign-systems (often artificially devised rather than being an organic sign language) to teach written English. But over the course of the century, hearing instructors at the asylums became engaged in a struggle to make deaf children forget visual-spatial forms of communication, both in the form of complex sign-languages, and, what the teachers scathingly discussed as 'gesture.' From the early nineteenth century, many educators of the deaf educationalists claimed 'Our object is ... to substitute our language for his' and bemoaned that 'it is very well known that while together, the deaf and dumb use nothing but the very language which we want them to forsake-gestures’ (Gordon 1831: 14). In 1880 the Second International Conference on the Deaf and Dumb in Milan decreed the abolition of sign-languages across Europe, and by 1900 every one of the 87 schools for the deaf in Britain had banned sign-languages both as a formal means of instruction and as a way of students communicating with each other outside class (Carpenter 2009: 139). The message was invariably reinforced by harsh physical punishments and the binding and beating of silent hands. Again we can see the interplay between remembering or creating and forgetting or destroying. Ironically, these were places that, by allowing many deaf children to come together for the first time, actually facilitated the rapid spread of manual sign languages.

There are other ways in which the tropes of forgetting that recurred in nineteenthcentury discussions of deafness seem to be tied to the development of these asylums, they can be read as 'spaces of forgetting.' Space has often been linked to ideas around memory. Historians of memory have powerfully demonstrated the ways in which space can be used 'to remember' and how, in Jay Winter's phraseology, we construct 'sites of memory' and 'sites of mourning' (1995). But space is also important for forgetting, as is demonstrated by the spatial imagery that saturates the language we use to discuss those who are 'marginal' to society, social 'outcasts,' or experiences that are 'peripheral' to what is held 'centrally.' Forgotten memories are sometimes discussed as 'spotless minds' or vacuous 'blank spaces' that need to be filled in. 
Space can facilitate forgetting through visually and conceptually obscuring the object, person or experience in question. The solid structures and closed walls of the deaf asylums hid deaf people from the outside world. The stern Victorian institutional architecture of the asylums with their high sturdy walls produced the illusion that disability itself could be identified and contained - the deaf could be set apart from the 'normal' people outside and then, hidden, and forgotten. Contemporary illustrations of such asylums seemed to magnify this effect, depicting them as isolated buildings with the impermeable walls (see figure 1). The spatial separation signified by these structures reassuringly evoked the idea of an 'actual' distinction between 'the disabled' and those disability activists have sometimes referred to as 'the temporarily able-bodied'; the walls of the asylums helped disability to be constructed as discrete and different.

Behind the walls, hearing observers imagined spaces that could easily be forgotten. Whilst the geographer of deafness, Mike Gulliver (2008) has argued that, at least in the French context, these asylums created what he calls 'DEAF space,' differentiated from the hearing world and filled with visual voices, these voices are not present in hearing representations, instead the asylums were constructed as places of silence.

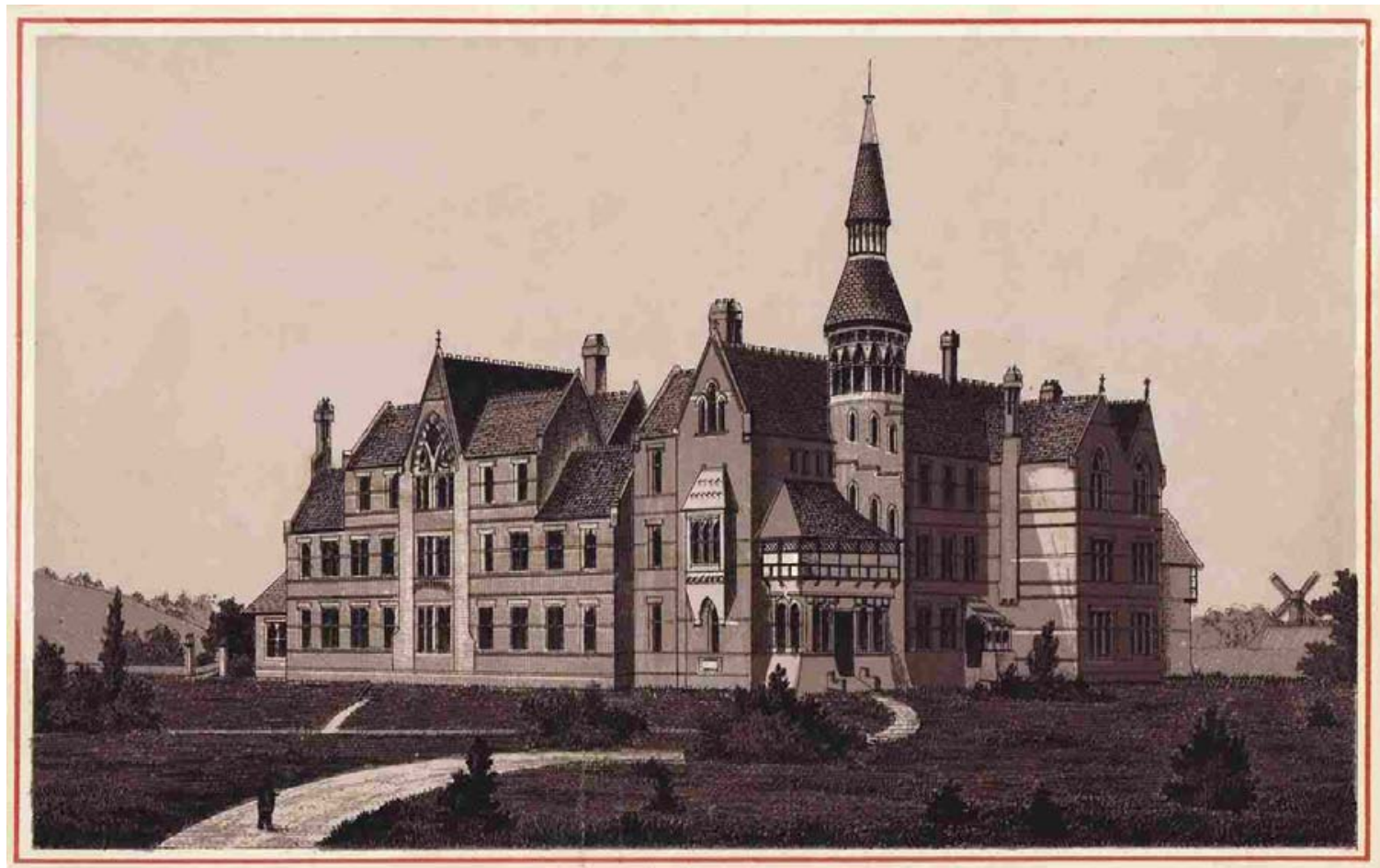

THE DEAF \& DUMB ASYLUM.

Figure 1: 'The Deaf \& Dumb Asylum,’ Margate, UK, in Charles, Reynolds and Co., The Album of Margate Views, Pre-1889. Online, available: http://www.margatelocalhistory.co.uk/Pictures/PrintsLeporello\%202.html [Accessed 31 January 2015]. 
Some hearing observers even went so far as to link the asylums with a place forgotten not only behind walls, but as far away, socially and emotionally, as an overseas territory. Joseph Hatton (1896: 6), for example, wrote on his ‘exploration’ of the Margate Deaf And Dumb Asylum (pictured above, figure 1) as the 'reminiscences of a sojourner in Deaf-and-Dumb Land,' a place he described as ‘A strange, sad, interesting country, a little world of little people.' The deaf were safely contained 'in there' and the allusion of physical distance seemed to relieve Hatton, and other interlopers into 'deaf-and-dumb lands,' of the suggestions of guilt implied passingly, of being born outside of this land.

The language that Hatton (1896: 41) used to evoke the 'Deaf-and-Dumb Lands' is strikingly reminiscent of the language of contemporary imperial travel writing, 'Deafand-Dumb Land is a new country to me,' he wrote:

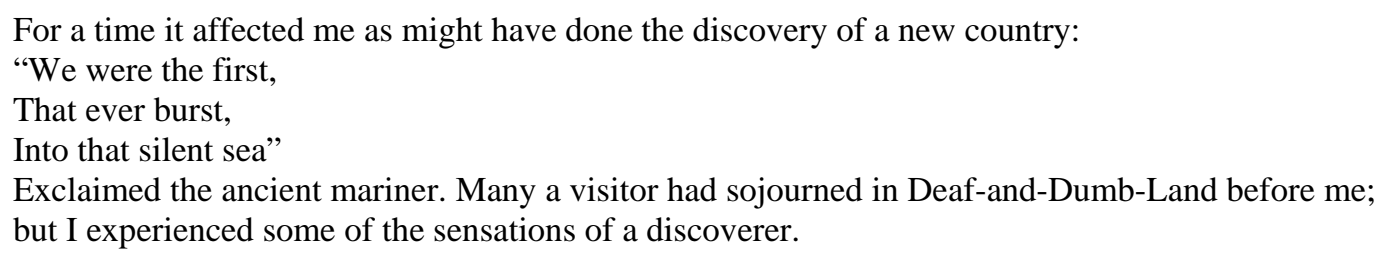

This imagery is not only about geographical distance but also about otherness, a linking that was increasingly mapped onto imperial frameworks in this period. In medical and colonial discourses the empire was also being increasingly linked to disease in this period: the 'hot' spaces of the colonies were being linked with sickness and a climate that Europeans could not survive; Africa was a 'sick continent' both epidemiologically and morally, and the peoples of empire were imagined as crying out for the rapidly advancing western biomedicine. In doing so, the empire offered a means through which to imaginarily transport the ills from the metropole out to the colonies. It was as though sickness and disability were themselves being conceptually exported to the colonies, as climatic understandings of disease increasingly identified Africa and India as 'places of sickness' and Britain as a place of relative 'health.' Such moves encouraged the forgetting of disability back home. It also meant that deaf people, and people with disabilities more widely, became associated with difference and with otherness. This difference 'at home,' as discussed in the first part of this article, was something that many were anxious to forget.

To some extent, the isolated buildings of the institutions for the deaf, 'cut off' from 'normal' humanity, mirrored or imitated the imagined remoteness of the deaf child as 
‘insulated and lonely’ (Account of the General Institution ... 1814: 25). Writers about the deaf had long deplored how, in the words of an Irish advocate of deaf education, the (uneducated) deaf-mute was 'excluded in this life from the circle of social enjoyment, doomed to pine away his years in solitary misery’ (Gordon 1831: iv). Hatton (1896: 9) reflected on the 'faces of deaf-mutes' he encountered in the Margate deaf asylum; he could 'imagine nothing more pathetic than the anxious look of a deaf-and-dumb child, the utter lost expression of it, the sense of being cut off from you, of being outside your world, a creature of an inferior order.' W. Roe, Headmaster at the Midland Deaf and Dumb Institution, similarly deplored that 'From the cradle they [deaf people] are cut off from their fellow creatures ... God only can know the bitterness of heart, the isolation of the deaf and dumb child of the poor, as it grows up in a world without speech or sound—a lifelong silence!' (Roe 1886: 3). One implication of this is the refusal of responsibility for the social process through which a deaf child could became ostracised and excluded; if the deaf child was 'isolated' from society, it was not the fault of society at large but the fault of the disability itself. This logic suggests that even outside of the asylum, the deaf were imagined to be distant and with this distance came the construction of difference and forgetting.

\section{Beyond the asylum: silence, invisibility and crises of representation}

The literary critic and disability theorist, Ato Quayson, has described what he terms the 'crisis of representation' that surrounds the literary portrayal of people with disabilities. Reflecting on a Scope advertisement depicting a man with cerebral palsy literally being looked straight through, Quayson discusses the apparent 'invisibility' of disabled people and argues that 'the problem is not one of not being seen ... but of being framed within a discourse of stereotypes and expectations that serve to efface a person's identity' (Quayson 2007: 2). That is to say, people with disabilities are seen only as their disability; their gender, ethnic, or class identities, for example, are forgotten because they are only seen as 'disabled.' Quayson draws on the work of Rosemarie GarlandThompson (1997) who analysed a process through which she claims the ability of a non-disabled person to engage with a disabled person is disrupted because in registering the disability, they effectively 'short-circuit' the absorption of all other forms of social information. These analyses have strong resonances with many of the ways in which people who are deaf are represented in nineteenth-century writings, the individuality of deaf people is easily forgotten as they are primarily represented as 'deaf and dumb.' 
Only the shedding of difference, represented in particular by the acquisition of written English, could bring an individual identity to light. One account told of a young deaf man once known only as 'troublesome dummy,' but, of whom, having spent some time in a deaf institution, it was reported that '[a]ll is changed; he is a nice clean, well behaved boy, and people are beginning to call him by his right name, William' (Roe 1886: 9).

Taking Quayson’s theory very broadly, there are several ways in which deafness could trigger a 'crisis of representation.' In quite the opposite way to how, before his 'education,' William was subsumed within the label of his disability, others found it was their disability itself that was surrounded by silence. This was particularly true beyond representations of working-class deaf people towards whom most of the philanthropic activity around deafness was aimed. Like all discourses of difference, disability is intersectional and is experienced differently as it interacts with race, gender and class. Writing of her experiences as a middle-class intellectual woman who became increasingly deaf from the age of 18, Harriet Martineau (1834: 252) complained that 'everybody helps, by false tenderness, to make the subject too sacred a one to be touched upon.' Silence here is not the muteness of a deaf person, still less Martineau who was renowned for her loquacity, but the 'dumbness' of her companions, unable to speak of the issue they feared. The misplaced tact or embarrassment here is not an inclusive overlooking but a refusal to acknowledge individual needs and identity. This ‘silence’ or 'crisis’ around Martineau’s deafness recalls the shame, discomfort and anxiety that often characterise other histories that have been forgotten.

Deafness does not fit Quayson's model of a 'crisis of representation' in the same way that physical deformity does, nor does the visual appearance of someone who was deaf trigger the kinds of shocked short-circuits that Garland-Thomson has explored. Indeed, the invisibility of deafness was sometimes seen as disconcertingly allowing deaf people to 'pass' as hearing. For philanthropists, the un-pitying image of 'normality' was also frustrating as it failed to entice the 'able-bodied' to donate to the cause of deafness. But for others, the 'sameness' of the face offered the potential to mitigate some of the otherness of deafness and symbolised a poignant silence. As a Reverend Kennedy put it in the early nineteenth century: 
[S] urely to a thinking mind their dumb mouths will plead more powerfully than the most eloquent efforts of speech; for as they wear like ourselves the human face divine, their wearing of it will be only a silent reproach to us, if we omit, when we have an opportunity, to confer on them some of those intellectual prerogatives of which that face is the proper index. (Cited in Account of the General Institution 1814: 27)

But, whilst sparing the deaf some of the stigma of deformity, this invisibility too could be problematic.

In her 'Letter to the Deaf' (1834), Harriet Martineau outlined her fears and frustration not of being excluded because her acquaintances saw her as different but because they forgot that she was so. Recalling the times she had been surrounded by chattering friends whose conversation she could not hear and whose laughter she imagined directed at her unhearing self, Martineau evoked the pain of being among friends and yet feeling isolated. Whilst her inability to join in and to follow the chatter seemed easily forgotten, 'we,' Martineau wrote embracing her deaf 'family,' 'cannot forget ... for five minutes together, that we spend in society'; the deaf, she suggested, were constantly reminded of what was easily forgotten (1834: 251).

Silence forms an equivalent crisis of representation for deafness and is also conceptually linked to forgetting. As Gulliver (2008: 90) notes, although misguided, the trope of silence is almost 'iconic' in hearing representations of deafness, used 'extensively' by hearing people to evoke the lives of deaf people and included in the title of many books, films and performances made by or about them. This was also the case in the nineteenth century, where deaf people were often called 'children of silence. ${ }^{3}$ But naming deaf people as 'silent' is poetic at best and actively silencing at worst. Deaf people are not silent, though during the nineteenth century, many deaf people were made to believe their voices were ugly and chose not to use them. The construction of deaf people as 'silent' beings brings to mind other people who have been silenced in British history not least the indigenous peoples of empire, whose voices, like those of the deaf, were often labelled 'unintelligible.' The lives of many of those defined through their difference were described, not as actively excluded, but as unable to 'speak up,' 'naturally' silent, and easily forgotten. But of course, silence does not necessarily indicate forgetting. Some of the most intense silences are generated around what cannot be forgotten and yet, to use the hearing metaphor, cannot be spoken.

\footnotetext{
${ }^{3}$ See for example George Tait’s autobiography, which is dedicated to the 'children of silence' (1878).
} 


\section{Conclusion: the tensions of finding and forgetting}

The writing of histories of forgetting and remembering is, like other history writing, intimately linked to the present, to the moment of recall. The early twentieth-first century is a complex and contradictory moment for the making and unmaking of Deaf identity and the writing of d/Deaf histories (Pray \& Jordan 2010). On the one hand, Deaf archives are growing rapidly, suggesting a renewed acknowledgement of and interest in the lives of deaf people. But in part, the archives are growing because many special deaf schools are being closed, deemed unnecessary by renewed insistence on 'mainstream' education and the demise of many Deaf clubs due to ageing populations and declining funding. Politically, socially and economically, deaf people are still being marginalised and, in the United Kingdom at least, this promises to increase as disability benefits are cut. Cochlear implants have been felt by many Deaf community groups to be a new way of mutilating deaf people, imposing a kind of hearing literally on those embodied deaf, and, in the words of some Deaf activists, contributing to the 'ethnocide' of a reproducing Deaf culture (Sparrow 2010). The rise of pre-gestation and antenatal genetic testing and the non-implantation of embryos and abortion of foetuses containing 'disabled' genes have led to further anxiety. A clause of The Human Fertilization and Embryology Bill, an Act of the Parliament of the United Kingdom in 2008, which sought to make it compulsory for IVF doctors to select a genetically 'healthy' foetus in IVF over an 'abnormal' or 'disabled' foetus, such as one that was deaf, was read by many Deaf activists as an attempt to eradicate the congenitally deaf from coming into being (Emery, Middleton \& Turner 2010). The campaign against it, called 'Stop Eugenics,' brings to mind Bell's desire that deaf people should not be born. This campaign spread rapidly via the internet, a medium that offers exciting new opportunities for remote visual communication and the formation of new deaf communities. Amidst these developments are many complex tensions between forgetting and remembering.

The nineteenth century was also a moment of complex interchange between inclusion and marginalisation. It was a period in western Europe and North America when 'the deaf and dumb' consolidated as a social category and significant social efforts were put into discovering, finding and remembering deafness. Yet it was also a period that saw new attempts to obscure and contain 'the deaf and dumb.' In the article I have discussed an illusion of containment of the anxieties through which those living with deafness and 
disability could be imagined to be a discrete and identifiable group, best kept out of sight. I have explored the 'crisis of representation' that surrounded discussions of deafness in other spheres. Like other peoples constructed as different, deaf people were represented as disruptive, potentially frightening, and often best forgotten. in posing deafness as something that should be forgotten, it was actively excluded and that through suggesting that the 'silent' deaf were 'easy to forget,' their displacement was in effect facilitated.

\section{Reference List}

Account of the General Institution Established in Birmingham, for the Instruction of Deaf and Dumb Children, Including Rules of the Society and a list of the Patrons, Officers, and Subscribers 1814, J. Ferrall, Birmingham.

Bell, A. 1883, Memoir upon the Formation of a Deaf Variety of the Human Race, Presented to the National Academy of Sciences at New Haven. National Academy of Sciences, Washington, DC.

Carpenter, M. 2009, Health, Medicine and Society in Victorian England. Praeger, California.

Census of England and Wales for the Year 1861

Census of England and Wales for the Year 1871

Census of England and Wales for the Year 1881

Cleall, E. 2013, “"Deaf to the Word”: Deafness, Gender and Protestantism in Nineteenth-Century Britain and Ireland,' Gender and History, vol. 25, no. 3 (November): 590-603. doi: http://dx.doi.org/10.1111/1468-0424.12027.

Emery, S., Middleton, A. \& Turner, G. 2010, 'Whose Deaf Genes Are They Anyway? The Deaf Community's Challenge to Legislation on Embryo Selection,' Sign Language Studies, vol. 10, no. 2 (Winter): 155-169. doi: http://dx.doi.org/10.1353/sls.0.0037.

Fitzgerald, K. 2010, Deafness of the Mind: The Forgotten Children of Boston Spa. Kevin Fitzgerald, Manchester.

Garland-Thomson, R. 1997, Extraordinary Bodies: Figuring Physical Disability in American Literature and Culture. Columbia University Press, New York.

Gordon, (Mr) 1831, Art of Instructing the Deaf and Dumb with Remarks on Existing Institutions for their Relief. O’Flanagan, Dublin.

Gulliver, M. 2008, 'Places of Silence,' in Making Sense of Place: Exploring the Concepts and Expressions of Place Through Different Senses and Lenses, (eds) F. Vanclay, M. Higgens \& A. Brackshaw. National Museum of Australia Press, Canberra: 87-95.

Hatton, J. 1896, Deaf-and-Dumb Land. Waterlow Brothers \& Leyton Limited, London.

Ladd, P. 2003, Understanding Deaf Culture: In Search of Deafhood. Multilingual Matter, Clevedon.

Lane, H. 1992, The Mask of Benevolence: Disabling the Deaf Community. Knopf, New York.

Martineau, H. 1834, 'Letter to the Deaf,' in Miscellanies. vol. 1. Hilliard, Gray, Boston: 248-265.

Morgan, R, 1999, 'Giving Voice to Silenced Lives: A South African Sign Language Oral History Project With the Deaf Community,' S. A. Archives Journal, vol. 41: 41-48.

Jackson, P. 2001, A Pictorial History of Deaf Britain. Deafprint Winsford, Cheshire.

Pray, J. \& Jordan, I. 2010, 'The Deaf Community and Culture at a Crossroads: Issues and Challenges,' Journal of Social Work in Disability and Rehabilitation, vol. 9, no. 2-3: 168-193. doi: http://dx.doi.org/10.1080/1536710X.2010.493486.

Quayson, A. 2007, Aesthetic Nervousness, Disability and the Crisis of Representation. Columbia University Press, New York.

Radstone, S. \& Schwarz, B. 2010, Memory: Theories, Histories and Debates. Fordham University Press, Bronx.

Roe, W. 1886, Anecdotes \& Incidents of the Deaf \& Dumb. Francis Carter, Iron Gate, Derby.

Society for the Propagation of Christian Knowledge [SPCK] 1864, To the Deaf Who on That Account Do Not Attend Church. SPCK, London.

Sparrow, R. 2010, 'Implants and Ethnocide: learning from the cochlear implant controversy,' Disability \& Society, vol. 25: 455-466. doi: http://dx.doi.org/10.1080/09687591003755849. 
Stoler, A. 2011, ‘Colonial Aphasia: Race and Disabled Histories in France,' Public Culture, vol. 23, no. 1: 121-156. doi: http://dx.doi.org/10.1215/08992363-2010-018.

Striker, H.-J. 1999, A History of Disability, (trans.) W. Sayers. University of Michigan, Michigan.

Tait, G. 1878, Autobiography of George Tait, A Deaf Mute. James Bowes \& Sons, Halifax.

Winter, J. 1995, Sites of Memory, Sites of Mourning: The Great War in European Cultural History. Cambridge University Press, Cambridge. 